\title{
Nest predation research: recent findings and future perspectives
}

\author{
J. D. Ibáñez-Álamo ${ }^{1,2} \cdot$ R. D. Magrath $^{3}$ J. C. Oteyza ${ }^{4}$ A. D. Chalfoun ${ }^{5}$. \\ T. M. Haff ${ }^{3}$ - K. A. Schmidt ${ }^{6}$ - R. L. Thomson ${ }^{7,8}$ - T. E. Martin'
}

Received: 10 December 2014/Revised: 28 January 2015/Accepted: 11 March 2015/Published online: 18 April 2015

(C) The Author(s) 2015. This article is published with open access at Springerlink.com

\begin{abstract}
Nest predation is a key source of selection for birds that has attracted increasing attention from ornithologists. The inclusion of new concepts applicable to nest predation that stem from social information, eavesdropping or physiology has expanded our knowledge considerably. Recent methodological advancements now allow focus on all three players within nest predation interactions: adults, offspring and predators. Indeed, the study of nest predation now forms a vital part of avian research in several fields, including animal behaviour, population ecology, evolution and conservation biology. However, within nest predation research there are important aspects that require further development, such as the comparison between ecological and evolutionary antipredator responses, and the role of anthropogenic change. We hope this review of recent findings and the presentation
\end{abstract}

Communicated by E. Matthysen.

J. D. Ibáñez-Álamo

j.d.ibanez-alamo@rug.nl

1 Animal Ecology Group, Centre for Ecological and Evolutionary Studies, University of Groningen, P.O. Box 11103, 9700 CC Groningen, The Netherlands

2 Dept. Wetland Ecology, Estación Biológica de Doñana, C.S.I.C, Avda. Américo Vespucio s/n, 41092 Sevilla, Spain

3 Division of Evolution, Ecology and Genetics, Research School of Biology, Australian National University, Canberra, ACT 2601, Australia

4 Wildlife Biology Program, Montana Cooperative Wildlife Research Unit, University of Montana, Missoula, MT 59812, USA

5 US Geological Survey Wyoming Cooperative Fish and Wildlife Research Unit, Department of Zoology and Physiology, University of Wyoming, Laramie, WY 59801, USA of new research avenues will encourage researchers to study this important and interesting selective pressure, and ultimately will help us to better understand the biology of birds.

Keywords Animal behavior - Conservation biology . Evolution · Nest predation · Population ecology

\section{Introduction}

Predation is one of the most important selective pressures in nature, shaping evolutionary relationships in many systems including birds (Caro 2005). The life of all birds is characterized by a critical stage in which they are bound to a particular location, the nest. The selective pressures acting during this period modulate their biology to a large extent.

6 Department of Biological Sciences, Texas Tech University, Lubbock, TX 79424, USA

7 Section of Ecology, Department of Biology, University of Turku, 20014 Turku, Finland

8 Percy FitzPatrick Institute of African Ornithology, DST/NRF Centre of Excellence, University of Cape Town, Rondebosch 7701, South Africa

9 US Geological Survey, Montana Cooperative Wildlife Research Unit, University of Montana, Missoula, MT 59812, USA 
Thus, it is not surprising that nest predation is considered a key source of selection for birds (Martin 1995).

Early arguments that nest predation can exert strong selection on species coexistence, habitat selection and life history strategies were met with skepticism (Ricklefs 2000). Avian ecology had focused on food limitation for a long period (Lack 1947; reviewed in Martin 1987, 1991), but a series of important papers championed the importance of predation (i.e. Moreau 1944; Skutch 1949; Martin 1988a, b, 1991, 1992, 1993a, b). Methodological improvements and new ecological perspectives have prompted many studies over the past 15 years, and these clearly demonstrate the importance of predation. For example, technology now allows researchers to monitor nests $24 \mathrm{~h}$ a day, which provides access to the identity and foraging behaviour of nest predators (e.g. Weidinger 2008; Benson et al. 2010). Advancements in our ability to measure physiological processes allow a better mechanistic understanding of the effects of nest predation risk, and the potential trade-off among different physiological systems within individuals (Zanette et al. 2014). Recent investigations on social information use by birds within communities have opened exciting new perspectives within this field (Dall et al. 2005; Seppänen et al. 2007; Schmidt et al. 2010). Furthermore, development of a more general predation framework has provided important new research challenges regarding nest predation, such as quantifying the magnitude of non-consumptive effects (the ecology of fear: Lima 1998; Cresswell 2008; Zanette et al. 2011). Indeed, the study of nest predation now forms a vital part of research in different areas, including animal behaviour, population ecology, evolution and conservation biology.

Our objectives are to highlight the relevance of nest predation within ornithology, discuss recent findings in the field, and address priorities for future research. Our aim is not to provide a comprehensive review; there are relatively recent reviews that cover different aspects of this field within the larger context of predation risk (Martin and Briskie 2009; Lima 2009; Magrath et al. 2010; Zanette et al. 2014). Rather, we provide insight into recent ideas and research that explore new aspects related to nest predation, or old aspects in light of recent conceptual advancements. We focus on studies directly addressing, or with clear implications to, nest predation, therefore not presenting those investigating predation in a broader sense.

\section{Adult antipredator strategies}

\section{Pre-nesting antipredator strategies}

Spatial and temporal variability in the risk of nest predation creates uncertainty for individuals about the quality of breeding territories or nesting sites. An informed breeding site choice can increase the probability of reproductive success, making settlement decisions vitally important. Indeed, predator removal experiments show that birds respond to the presence of predators by altering settlement decisions (Fontaine and Martin 2006), and also alter settlement to experimental changes in habitat that alter predation risk (LaManna et al. 2015). How birds acquire information about nest predation risk before selecting nest sites is a topic of increasing research. In this section we explore the cues or information that individuals use to assess spatial and temporal heterogeneity in nest predation risk prior to settling for breeding and nest initiation. Understanding these cues provides insight into how nest predators can structure avian communities and demography.

\section{Cues provided by nest predators}

Indirect proximate cues of predator activity may be used by settling birds to avoid areas with nest predators. Avian prey respond to acoustic cues from predators (e.g. Zanette et al. 2011) and brood parasites (Forsman and Martin 2009), so that acoustic cues may provide reliable information about the presence of nest predators. For example, ground-nesting passerines eavesdrop on communication calls of Chipmunks (Tamias striatus), with lower nest densities found near playback sites (Emmering and Schmidt 2011). Acoustic cues of potential nest predators have also been shown to affect Siberian Jay (Perisoreus infaustus) and Orange-Crowned Warbler (Vermivora celata) decisions about nest location decisions (Eggers et al. 2006; Peluc et al. 2008). Natural environments can have several different predators, and birds appear able to incorporate acoustic cues of predators of both adults and nests during settlement (Hua et al. 2013).

Birds use olfactory cues and light reflected in the UV range in many activities, such as mate choice and foraging (reviewed in Hagelin and Jones 2007; Roth et al. 2008; Rajchard 2009; Caro and Balthazart 2010). Recent studies suggest that such cues may be important in settlement decisions too, particularly for detecting nest predator species that are non-vocal and nocturnal. At the territory scale, settling passerines and ducks avoided areas experimentally treated with nest predator urine and faeces, which simulated predator presence (Eichholz et al. 2012; Forsman et al. 2013). Similar cues may be used by ground-nesting Wood Warblers (Phylloscopus sibilatrix), which appear to avoid outbreaks of rodents that may in turn attract high densities of nest predators (Wesołowski et al. 2009; Szymkoviak and Kuczyński 2015). Indeed, several studies have used urine of potential nest predators sprayed onto nest boxes as a nest predator treatment, and have found responses consistent with a perceived increase in risk of 
nest predation (Amo et al. 2008, 2011; Mönkkönen et al. 2009; Morosinotto et al. 2012). For example, nest boxes sprayed with mustelid urine are avoided (Mönkkönen et al. 2009). The mechanism used by birds to detect urine (odour, UV reflectance or both) is currently unknown. Research should focus on determining what cues are detected and used by settling birds to decrease probability of nest predation.

\section{Protector species}

Species vulnerable to nest predation may nest near aggressive species or predators that provide protection against nest predators (reviewed in Quinn and Ueta 2008). Protector species may serve as cues for low nest predation rates and may affect settlement decisions aimed at gaining safe nesting sites. Despite the generally clear reproductive benefits such associations entail (see Appendix 1 in Quinn and Ueta 2008), surprisingly few studies have experimentally demonstrated active choice in nest site selection in this context. Protective associations do not necessarily entail attraction at only small spatial scales; settling forest songbirds appear to preferentially select intermediate "optimal" distances from avian predator nests where the protective benefits against nest predators can represent a trade-off with the direct costs of being near the protector species (Thomson et al. 2006; Mönkkönen et al. 2007). Also bird species within the same guild may associate with each other during breeding to gain protective benefits (Kleindorfer et al. 2009; Campobello et al. 2012; Polak 2014); to date, these within-guild breeding associations have likely been overlooked, and deserve more attention in future. It would be fruitful to determine if prey actively choose to associate with other species for protection at different spatial scales, and the mechanisms involved in such associations, especially given the recent emphasis on positive interactions in avian communities.

The value of apparently protective associations may be dependent on the environmental context, and 'protected' nests may become prey when the abundance of alternative prey for the 'protective' predator declines (Dunn 1977; McKinnon et al. 2014). For example, fluctuating prey densities in different years appeared to alter the protection benefits to ground nests provided by Ural Owl (Strix uralensis; Häkkila et al. 2012), which may also attract mesopredators seeking protection. This can in turn increase nest predation rates for 'protected' species (Morosinotto et al. 2012). Associations between species may also entail reciprocal protective relationships, for example the mixed breeding colonies of Lesser Kestrels (Falco naumanni) and Jackdaws (Corvus monedula) where both species decrease vigilance when in mixed colonies (Campobello et al. 2012). Overall, the use of protector species and their impact on territory and nest site selection is probably underestimated, and might prove to be an important tool in species management (Fletcher 2008).

\section{Assessing the success of others}

Settling birds may use the presence or success of conspecifics and heterospecifics as proxies of nest predation risk. Assessing territories and nest sites both during (Parejo et al. 2008; Thomson et al. 2013) and following breeding attempts may affect breeding location decisions the following year (Boulinier and Danchin 1997; Doligez et al. 2002; Pärt et al. 2011). Prior to breeding, later arriving individuals can also assess the quality and success of earlier conspecific and heterospecific birds, and select nest sites that have features associated with success (Seppänen and Forsman 2007; Seppänen et al. 2010; Loukola et al. 2012).

\section{Personal success as information}

Birds can use personal reproductive performance as a guide to future habitat selection (e.g. Chalfoun and Martin 2010a; Pakanen et al. 2014). The "win-stay:lose-switch" strategy, proposed by Hildén (1965) and Greig-Smith (1982), suggests that individuals should return to a breeding site if successful, but leave if not. This hypothesis was originally tested in relation to patch-scale fidelity (e.g. Bollinger and Gavin 1989; Hoover 2003), a scale at which it might be an evolutionary stable strategy (Schmidt 2001). However, the win-stay:lose-switch rule is likely to operate at multiple scales, including within patches (Chalfoun and Martin 2010a; Kearns and Rodewald 2013), where individuals can reuse or change nest sites both between and within years.

The win-stay:lose-switch rule is also simplistic in some contexts because individuals are likely to benefit from taking a longer view of success than just the most recent breeding attempt. For instance, Piper (2011) has suggested the concept of site familiarity, in which individuals gain 'private value' based on their broader experience within a site. Similarly, individuals might follow a Bayesian updating rule that is cumulative over different nest attempts (Schmidt and Whelan 2010), which could be particularly important if individuals renest multiple times within a season (Pakanen et al. 2014). And as a Bayesian process, the posterior estimate of habitat quality accounts for the other information on distribution of quality among sites or habitats. These possibilities could be tested because, for instance, the Bayesian rule predicts birds will be less likely to alter habitat selection as a result of recent failure if they have a higher prior estimate of site quality, which could be manipulated experimentally.

Last, assessing conspecific success (see section "Assessing the success of others") can be seen as the 
extension of using personal success as information, and the two strategies may co-occur (Doligez et al. 2003) or the latter may supplement personal success, especially in colonial breeders (Boulinier and Danchin 1997).

Understanding individual habitat selection strategies, however, is not the same as understanding breeding habitat selection at the population level. As a result of frequencydependent feedback from the action of other individuals a population may consist of individuals using different strategies. For example, those used by information producers or scroungers (Doligez et al. 2003), strategies which may be contingent on success or the fidelity of conspecifics (Pärt et al. 2011), and different strategies based on the effort (e.g. time) invested in collecting information which will depend on the intensity of competition for breeding sites (Schmidt et al. 2015).

One potentially fruitful approach to look beyond individual strategies is through the analogy of choosing a coloured ball (or balls at the population level) from an urn under the constraint that sampling is without replacement and (i.e. choice of breeding site) is biased. Information from pre- or post- and personal or conspecific breeding cues, or any inherent preference, is reduced to sampling bias (Schmidt et al. 2015). This approach is amenable to a game-theoretical analysis of breeding habitat selection that extends to investigating the ecological and evolutionary consequences of environmental change. For example, as population densities decline in degraded environments individuals are expected to invest more time in information gathering and exhibit greater bias toward selecting good sites. This suggests that information-gathering strategies have the capacity to ameliorate environmental change (Schmidt et al. 2015).

\section{Antipredator strategies during the nesting stage}

After settlement decisions are made, parents can adjust their breeding strategies in response to changes in nest predation risk (reviewed in Martin and Briskie 2009). Indeed, many of these proximate shifts in parental care behaviours have been the focus of recent studies, such as changes in incubation patterns (e.g. Chalfoun and Martin 2010b; Ibáñez-Álamo and Soler 2012; Morosinotto et al. 2013a) and offspring provisioning rates (e.g. Zanette et al. 2011; Ghalambor et al. 2013; Mutzel et al. 2013; Hua et al. 2014). The norm regarding these parental care traits is to reduce activity in response to increased predation risk, at least in ecological time. See below for the contrast between these responses and those obtained in evolutionary time.

Although the increased risk of predation has a predictable effect on incubation patterns and provisioning rates, it is less clear how risk affects egg mass and clutch size. There is a trade-off between egg size and number
(Smith and Fretwell 1974) and are both expected to decrease under increased nest predation risk (Martin et al. 2006; Martin and Briskie 2009). Despite this, recent studies on temperate passerine birds that experimentally manipulated predation risk found contrasting results. For example, Fontaine and Martin (2006) found that when predation risk was higher, females of eight species did not change clutch size but laid smaller eggs, which caused lower clutch masses. Conversely, other studies found a reduction in clutch size (Eggers et al. 2006; Travers et al. 2010; Zanette et al. 2011; Hua et al. 2014), and an increase in egg mass (Zanette et al. 2011) or no change in clutch mass (Hua et al. 2014) when predation risk was increased. The discrepancies among these results highlight the need for further tests. Changes in clutch size are potentially favoured over changes in egg mass since a decrease in clutch size represents a more significant decrease in energy investment-with fewer eggs to produce, incubate, and young to feed-than changes in egg mass (Martin et al. 2006). The dissimilar results found by Fontaine and Martin (2006), where birds adjusted egg mass but not clutch size, may be explained by a key methodological difference among experiments. Unlike the other four studies that increased risk, Fontaine and Martin (2006) decreased risk for eight species. Increases in clutch size with decreased risk represents a substantial increase in reproductive effort and, thus, may be constrained, whereas species may more readily decrease clutch size and associated reproductive effort when risk increases. Effects of opposing directions of risk on reproductive output have not been directly tested. Furthermore, species that already have very small clutch sizes, such as those in the tropics, may be constrained and less likely to further decrease clutch size in response to predation and may instead show changes in egg mass (Martin et al. 2006). These ideas require further testing to elucidate which factors may constrain or modulate parental responses in egg investment to changes in nest predation risk.

\section{Offspring antipredator strategies}

In contrast to their parents, who have active antipredator strategies, offspring are often seen as passive victims. Skutch beautifully captured this image of defenceless young when he wrote of naive nestlings begging when disturbed: "Doubtless they greet in this trustful manner the snake or squirrel that comes to devour them" (Skutch 1976). In this section we show that while young are certainly vulnerable, they are not helpless, but instead engage in a variety of behaviours to thwart predators. We focus particularly on the relatively recent issue of how young gain information about current risk from multiple sources, 
including parents, predators and from other prey species. We suggest that research will benefit from taking a nestling's view of the world.

\section{Antipredator behaviour}

Young can thwart predators in a diversity of ways, including by reducing the risk of detection, recruiting parents, actively repelling predators, and fleeing (reviews: Skutch 1976; Martin 1992; Lima 2009; Magrath et al. 2010). Nestlings can reduce the risk of detection by crouching low in the nest and becoming silent if a predator is near, and begging calls themselves can be difficult for predators to overhear or locate, or young may beg silently (Wegrzyn and Leniowski 2015). Young can recruit parents through loud distress calls, which might also warn siblings. Distress calls could also repel predators, and some young appear to deter predators by mimicking dangerous species, such as Burrowing Owls (Athene cunicularia) producing sounds that resemble rattlesnakes (Rowe et al. 1986; Owings et al. 2002), and Northern Flickers (Colaptes auratus) sounding like a hive of bees (Wiebe and Moore 2008); however, these ideas remain to be tested (Dalziell et al. 2014). Nestlings can also use chemical defence (reviews: Dumbacher and Pruett-Jones 1996; Hagelin and Jones 2007). For example, Eurasian Hoopoe (Upupa epops) nestlings produce malodorous fluid from oil-glands and eject liquid faeces against potential nest predators (Glutz Von Blotzheim and Bauer 1980). The effectiveness of chemical defence has recently been experimentally tested for young Eurasian Rollers (Coracias garrulus), which vomit a cocktail of chemicals that deters dogs (Parejo et al. 2013), and for Great Spotted Cuckoos (Clamator glandarius), which defend themselves with a cloacal secretion containing a mixture of chemicals that deters both mammalian and avian predators (Canestrari et al. 2014). Finally, older nestlings commonly "explode" from the nest and seek cover if the nest is attacked.

\section{Gathering information}

When young have several options available, the choice of which defensive strategy to deploy may depend on the type of threat, opening up new opportunities for research on the perceptual and decision-making abilities of nestlings. Here we focus on information gained from sound, as this is valuable even before their eyes are open, as well as in enclosed nests or dense cover.

\section{Information from parents}

The most obvious source of information is from parents, whose alarm calls can warn young of danger (reviews:
Martin 1992; Caro 2005; Magrath et al. 2010). Nestlings commonly become silent after playback of parental alarm calls, showing that young respond to the signals themselves. Although responding to parental calls might seem a "passive" response compared to their parents' "active" delivery of calls, communication requires the evolution of both signals and responses (Maynard Smith and Harper 2003), so the behaviour of young is best seen as active use of available information.

The active role of young in response to parental calls is best illustrated by differences in behaviour according to the type of danger or stage of development. Most dramatically, Great Tits (Parus major) respond differently depending on the type of parental alarm call, and therefore type of threat (Suzuki 2011). Young crouch at the bottom of their nest cavity when parents warn of crows, but flee the nest when parents give a different alarm call warning of snakes. These contrasting responses make sense because crows can reach into cavities but cannot enter nests, so crouching can avoid a probing beak, whereas snakes can enter nests and so young must flee. Similarly, White-Browed Scrubwren (Sericornis frontalis) nestlings become silent in response to parental mobbing calls warning of predators on the ground, but ignore aerial alarms to raptors flying overhead (Platzen and Magrath 2005). This difference is consistent with their vulnerabilities, because nests are cryptic, enclosed structures, placed on the ground and invisible from above. As soon as young leave the nest, however, they become highly responsive to aerial alarms (Magrath et al. 2006).

\section{Information from predators}

In addition to relying on calls from parents, young could gather information on risk from predators themselves. Adult vertebrates often recognize the vocalizations or other cues of predators (Hettena et al. 2014), but there is extremely little known about young. However, young birds can use acoustic cues from predators. Most White-Browed Scrubwren nestlings become immediately silent in response to playback of the sound of a predatory bird walking in leaf litter near the nest, which is similar to their response to parental alarm calls (Magrath et al. 2007). This response appears specific to the context of predation, since non-alarm vocalizations of parents and a variety of novel sounds prompt little or no call suppression in nestlings (Haff and Magrath 2010). This raises unanswered questions of generality and mechanism.

\section{Information from other species}

As well as listening to parents and detecting predators directly, young can gain information by eavesdropping on the alarm calls of other prey species, but it is not yet clear if 
this is widespread. Eavesdropping on species with shared predators should be beneficial, and it could also be common, given that the adults of many species do eavesdrop on heterospecific alarm calls (reviews in Seppänen et al. 2007; Goodale et al. 2010; Magrath et al. 2014).

Among the few species studied, young nestlings usually respond only to conspecific alarm calls unless heterospecific alarm calls are very similar (e.g. Davies et al. 2004; Madden et al. 2005; Haff and Magrath 2012), but older nestlings may also respond to dissimilar heterospecific alarm calls. For example, White-Browed Scrubwren nestlings respond to the mobbing calls of conspecifics and one acoustically similar species when young, but respond to two other species with acoustically different calls later in the nestling period (Haff and Magrath 2012). There is a similar pattern among fledglings. Recently fledged young ignore heterospecific aerial alarm calls but do respond 2 weeks later, unless the heterospecific is rare on the territory (Haff and Magrath 2013). This suggests that young learn to recognize the alarm calls of common heterospecifics.

\section{The predator point of view}

In addition to adults and offspring, there is a third player in nest predation events: the nest predator. The predator perspective has been partially neglected in studies of predation risk (Schmidt 1999; Chalfoun et al. 2002a, b; Lima 2002). Within nest predation research, however, predators gain focus in part because cameras permit non-stop monitoring of bird nests. This allows for predator identification (Cox et al. 2012a), and an understanding of how predators find nests (Pelech et al. 2010). Nevertheless, there is minimal knowledge of many aspects of nest predator foraging habits, the mechanisms of locating nests, interactions between nest predators and habitats, and the importance of nest contents as food to individual predators (but see Schmidt et al. 2001; Schmidt and Schauer 2007).

Monitoring of bird nests has permitted individual predator species to be identified, and their prevalence and role in nest losses to be quantified (Cox et al. 2012a, b). Nest monitoring by cameras seems to be generally safe for nests (Weidinger 2008; Richardson et al. 2009; IbáñezAlámo et al. 2012), but validating this assumption in specific studies is important. Predator identification should be a critical starting point to studies investigating nest predation responses of a species or community to nest predation (e.g. Weidinger 2009). Knowing predator identity allows for better understanding of the selective pressures influencing parental and offspring antipredator strategies. Both cameras and dataloggers can provide insight into temporal patterns of predation, both within a day (e.g. crepuscular, diurnal, nocturnal) and during the nesting cycle (Libsch et al. 2008; Biancucci and Martin 2008; Weidinger 2010). Predators may have different preferences or abilities to handle nest contents, such as in the case of highly specialized egg-eating snakes (e.g. Gartner and Greene 2008) or raptors that may prefer to eat nestlings over eggs (Cox et al. 2012b), which may in turn favour completely different antipredator adaptations. Indeed, nonspecific nest predation data obscure potentially important aspects of the ecology of predators that limit understanding of avian responses to nest predators (Benson et al. 2010). Certainly some nest predation events are opportunistic (Schmidt 2004), but nest predators can use prior experience to learn nest site locations (Sonerud and Fjeld 1987; Pelech et al. 2010; Weidinger and Kočvara 2010).

Nest predators likely use a variety of predator-specific strategies and cues to find nests. Parental activity is one visual cue predators use to find nests. Several studies show that parents decrease activity under increased nest predation risk (see "Ecological versus evolutionary strategies"). The conspicuousness of the nests itself or the colours of the eggs may also attract the attention of visually oriented predators (Cott 1940; Tinbergen et al. 1962; Weidinger 2001; Kilner 2006; Biancucci and Martin 2010; Stoddard et al. 2011). Acoustic cues are generated around nests and are used by predators, and nesting birds respond by decreasing these cues in high risk situations (see "Offspring antipredator strategies"). Begging nestlings may attract predators (e.g. McDonald et al. 2009; Haff and Magrath 2011; Ibáñez-Álamo et al. 2012), and novel research suggests that nestlings of some species with high nest predation risk may beg silently (Węgrzyn and Leniowski 2015). Mobbing calls by parents at or near nests can also attract predators (Krama and Krams 2005; Krams et al. 2007; Bonnington et al. 2013), and indeed all acoustic communication by birds near the nest may be risky (Haff et al. 2015). Olfaction too has received recent attention. For example, alien predator Black Rats (Rattus rattus) can use odour to find bird nests, and this can be exploited as a management tool (Price and Banks 2012). Exposing rats to nest odours in an area prior to placing artificial nests caused non-associative learning that decreased subsequent nest predation rates. However, the presence of an obvious source of odour in nests, faecal sacs, did not seem to increase nest predation risk in blackbirds (Ibáñez-Álamo et al. 2013, 2014).

For birds nesting in environments with multiple nest predators, the challenge for parents and offspring is to limit the availability of cues used by predators. Understanding and quantifying the relative importance of these predation mechanisms will reveal how predation risk varies spatially and temporally, and improve our understanding of parental and offspring responses to changes in risk. In addition, nest 
predators may actively hide inadvertent information of their presence (e.g. Loukola et al. 2014), and so open novel co-evolutionary pathways between birds and nest predators.

\section{Physiological effects of nest predation}

The physiological mechanisms by which predation could shape traits of animals have gained increasing attention in recent years, although they are still poorly understood (Sheriff and Thaler 2014). This is also true for nest predation, which constitutes only a small proportion of studies in birds (reviewed in Zanette et al. 2014), with most focus on behavioural or evolutionary changes instead (see above and below respectively). Nevertheless, the physiology of antipredator strategies is important because it allows the measurement of previously unconsidered costs, and may reveal interactions between nest predation and other selective pressures (e.g. Schwabl et al. 2007; Coslovsky and Richner 2011a).

\section{Effects on adults}

The most studied physiological effects of nest predation are on adult hormonal modifications. For example a comparative study including six North American passerines found that species with higher nest predation risk had higher baseline corticosterone levels, but this effect was not maintained at the intraspecific level as adults did not change their corticosterone levels when nest predators were removed from experimental areas (Fontaine et al. 2011). Similarly, other studies failed to find changes in hormone levels after experimental manipulation of nest predation risk (Silverin 1998; Butler et al. 2009). In contrast, Song Sparrow (Melospiza melodia) adults subjected to frequent nest predation or breeding in risky areas did increase their corticosterone levels (Clinchy et al. 2004, 2011; Travers et al. 2010). The results suggest that there is no general pattern in adult hormonal response to nest predation risk, probably due to the costs associated with some hormones (e.g. Kitaysky et al. 2003; Saino et al. 2003).

Antipredator behaviour could also place energetic demands on parents. Reduced food intake of "fearful" adults or lower male feeding of incubating females could affect their physiological state (Fontaine and Martin 2006; Zanette et al. 2013). Furthermore, changes in offspring development rates due to nest predation risk might reduce (i.e. fewer parental care behaviours) or increase adult energetic demands too (i.e. through maternal effects; see below), an interesting possibility that is worthy of further research.

Changes in the immune system or in oxidative stress might be other physiological costs of nest predation. In fact, Song Sparrows when breeding in areas of high perceived nest predation risk showed an increase in basophils, but no elevation in heterophil to lymphocyte ratio suggesting that only some components of the immune system are affected by this selective pressure (Clinchy et al. 2004). Furthermore, frequent nest predation suppresses the immune system of female Song Sparrows, perhaps as a response to the threat of predation or the increased cost of egg production (Travers et al. 2010). These two studies also found increased oxidative stress in response to nest predation, which is consistent with the response to predation risk in general (reviewed in Constantini 2014). Nevertheless, more experimental studies across different species are needed to generalize about patterns of changes in the immune system or antioxidant protection. Comparative analyses will be especially valuable.

\section{Effects on offspring}

\section{Direct effects of nest predation on offspring}

The impact of nest predation risk on the endocrine system of nestlings seems to depend on the cues they perceive. Direct acoustic cues of nest predators decreased corticosterone but increased testosterone levels in the Common Blackbird (Turdus merula), suggesting that hormones might mediate begging activities according to perceived risk (IbáñezÁlamo et al. 2011). However, conspecific alarm calls did not modify hormonal profiles in other species (Dufty and Crandall 2005; Rivers et al. 2011), and nestling distress calls produced elevated corticosterone levels only in older nestlings (Fridinger et al. 2007; Tilgar et al. 2010). This highlights the relevance of offspring age in the ability to respond, at least physiologically, to nest predation risk.

The immune system and risk of nest predation seem to be linked in nestlings. The cell-mediated immune response of Campo Flicker (Colaptes campestris) nestlings affects their ultimate antipredator strategy when captured by a potential predator: individuals with higher immune ability give louder distress calls, which could indicate a healthier status aimed at attracting potential adult defenders (Goedert et al. 2014). Part of the nestling immune system seems to be impaired by nest predation; the heterophil to lymphocyte ratio increased when chicks were exposed to conspecific nestling distress calls, suggesting that they were physiologically stressed (Tilgar et al. 2010). Nevertheless, it is still untested whether other less extreme manipulations could elicit changes in the immune response of offspring. For a broad understanding of these effects it is important to quantify not only single measures of the immune system but also different components simultaneously as recommended by experts in the field of ecoimmunology (e.g. Matson et al. 2006). 
Nest predation effects on offspring mediated by adults

Risk posed by nest predators can affect offspring physiology indirectly through their effects on parents, such as through maternal effects (e.g. Martin and Schwabl 2008). Adult predation risk may affect the performance of offspring (e.g. Coslovsky et al. 2012), but only two studies have tested the effect of nest predation risk itself. For example, high levels of testosterone and $5 \alpha$-dihydrotestosterone in eggs are positively correlated with nest predation risk in 25 songbirds (Schwabl et al. 2007). Moreover, Pied Flycatchers (Ficedula hypoleuca) laying eggs in sites with nest predator cues transferred more immunoglobulins to their eggs while lysozyme and carotenoid levels remained unchanged (Morosinotto et al. 2013b). These results suggest that mothers could be preparing offspring for an environment with a high risk of nest predation. However, a distinction between allocation (adaptive) and transfer (nonadaptive) is needed, as female flycatchers under adult predation risk also show higher immunoglobulin levels (Thomson et al. 2010), and therefore the adaptive significance of these changes in egg composition remains unknown.

In addition to maternal effects on egg composition, adults could affect the energetic demands of their offspring by means of changes in their incubation or brooding patterns (Martin et al. 2007; Martin and Schwabl 2008) or in their food delivery (see below). These parental effects, in turn, may interact with trade-offs in development of phenotypic traits to influence embryo and nestling development (e.g. Coslovsky and Richner 2011b; Cheng and Martin 2012; Martin 2014). Indeed, despite the strong relationship between development strategies and the risk of nest predation (von Haartman 1957; Remeš 2007; Martin et al. 2007,2011 ) the underlying physiological mechanisms need further work. It is also important to consider differences between ecological and evolutionary responses, as the physiological traits that could be modified might differ.

\section{Ecological versus evolutionary strategies: time scale matters}

The influence of nest predation risk on the expression of life-history traits can reflect both proximate responses via phenotypic plasticity and evolved responses (reviewed in Martin and Briskie 2009). Proximate responses through phenotypic plasticity can allow fine-tuned responses to changing risk in ecological time. However, the extent of phenotypic adjustments can be constrained by trade-offs related to the evolved expression of traits, which differ among species (Martin and Briskie 2009). Moreover, the fitness consequences of shifts in a trait can differ dramatically in ecological versus evolutionary time (Martin et al. 2015).

Phenotypic plasticity responses to nest predation risk of the same trait can clearly differ among species. For example, several songbird species responded to a taxidermy model of a nest predator by decreasing the rate at which they fed their young (Ghalambor et al. 2013). On its own, this result is not surprising since several experiments have demonstrated decreased provisioning with increases in nest predation risk (reviewed in Martin and Briskie 2009; see also: Zanette et al. 2011; Mutzel et al. 2013; Hua et al. 2014). However, species differed strongly in the degree of their plasticity responses to the perception of increased nest predation risk (Ghalambor et al. 2013). This variation in plasticity across species highlights issues for further work. First, plasticity itself (or reaction norms) can evolve differentially among species and may be related to intensity of nest predation risk (reviewed in Martin and Briskie 2009; Ghalambor et al. 2013). For example, species that use relatively safe cavity nests may exhibit less plasticity than species that use riskier open-cup nests. Second, the extent of plasticity may also differ because of constraints imposed by trade-offs with other traits. For example, provisioning plasticity in response to nest predation risk may be constrained by food needs of growing nestlings, and also modified by the number of nestlings and their evolved growth rates (Martin et al. 2011; Mutzel et al. 2013). Third, fitness costs of proximate changes in expression of traits can differ among species as a function of evolved physiological mechanisms (see below; Martin et al. 2011). Thus, differences among species in plasticity, and the costs and trade-offs, remain a relatively unexplored area in need of more research.

Fitness costs of changes in traits can differ strongly for proximate versus evolutionary responses, but these differences have not received sufficient attention. For example, increased nest predation risk can yield a decrease in provisioning rate in both ecological time through plasticity (reviewed in Martin and Briskie 2009; also Zanette et al. 2011; Mutzel et al. 2013; Hua et al. 2014), and in evolutionary time as seen among species (Martin et al. 2000, 2011). Reductions in provisioning in response to increased predation risk in ecological time can yield poorer quality and slower growth of nestlings (e.g. Zanette et al. 2011). Increased nest predation is expected to favour faster growth in evolutionary time (Lack 1948; Bosque and Bosque 1995; Martin 1995; Remeš and Martin 2002), and species with greater nest predation risk evolve faster growth and an associated reduction in provisioning rates (Martin et al. 2011). The reduction in food delivery in high risk species compared with low risk species does not carry the costs observed from reduced food delivery in ecological time. The costs of reduced food delivery in ecological time 
within a species cannot be easily ameliorated because the developmental program (interaction and trade-offs among physiological and morphological traits) has evolved as an integrated whole. Over evolutionary time, however, tradeoffs among physiological and morphological traits can shift to facilitate faster growth despite reduced food (Cheng and Martin 2012).

Another example of the differences in fitness costs of shifting traits in ecological versus evolutionary time is provided by further consideration of growth rate. Evolution of faster growth, as expected from increased nest predation risk, is thought to create physiological costs that lead to greater adult mortality and shorter life (McCay 1933; Rollo 2002; Metcalfe and Monaghan 2003). Tests within species have demonstrated shorter life with proximate increases in growth rates (e.g. Rollo 2002; Olsson and Shine 2002; Lee et al. 2013). Yet, comparisons across species showed no relationship between growth rate and adult mortality rates (Martin et al. 2015), potentially because changes in growth rate over evolutionary time can allow evolutionary shifts in other traits, such as the fatty acid composition of mitochondrial cell membranes, which can offset physiological costs of faster metabolism and growth (e.g. Hulbert et al. 2007). Such physiological systems are likely much less plastic in ecological time, and thereby create constraints that impose costs to shifts in growth rates in ecological time that are not observed in evolutionary time.

Of course, shifting traits even in evolutionary time can come with costs related to trade-offs among traits and, thereby, influence evolution of other traits. For example, bird species that evolved under greater risk of nest predation may shorten the time they stay in the nest, and young may leave the nest (fledge) at an earlier developmental state (von Haartman 1957; Martin 2014). While leaving the nest quickly might minimize nest predation risk, the reduced developmental state may also create costs to survival of young after they leave the nest, as well as parental effort in raising those young, all of which might influence evolution of clutch size (Martin 2014). These interactions among traits and their fitness costs can influence evolution of life-history strategies and constrain the extent of phenotypic plasticity in tests of responses to changing predation risk within species.

Finally, life-history trait responses to nest predation in both ecological and evolutionary time may be modulated by differences among species in adult mortality. Life-history theory suggests that life-history strategies should respond to age-specific mortality (e.g. Law 1979; Michod 1979; Charlesworth 1980; Martin 2002, 2004). In particular, parental effort is expected to increase with increasing adult mortality, but decrease with increasing offspring mortality (Law 1979; Michod 1979; Charlesworth 1980; Martin 2002, 2004). This interplay of adult and offspring mortality on expression of life-history traits has received insufficient attention.

\section{Human impacts and conservation issues of nest predation}

Habitats worldwide continue to change rapidly, which can alter historic predator-prey relationships. Human-induced rapid environmental change can result in habitat loss, habitat fragmentation and/or alteration of remaining habitat patches, all of which can alter nest predation risk in comparison to contiguous patches of similar habitat devoid of human interference. Patterns of nest predation in relation to various forms of anthropogenic change, however, have been mixed. A huge body of literature, for example, has focused on nest survival in relation to different types of habitat edges, with varied and context-specific results (e.g. Lahti 2001; reviewed for tropical areas in Vetter et al. 2013). Urbanization and agricultural activities can influence nest predation, especially via the provision of food subsidies to predators. The directionality of such effects, however, depends on the main predators and whether subsidies translate into higher or lower nest predation pressure (Tomiałojć 1979; Chace and Walsh 2006; Benson et al. 2010; Ibáñez-Alámo and Soler 2010a; Rodewald et al. 2011). In some cases, management activities geared towards other species, such as ungulate feeding stations, can attract nest predators and inadvertently increase nest predation risk (Selva et al. 2014). Extraction of energy resources continues to be an expanding human land use, and has also yielded contrasting nest predation patterns. Nest predation rates of three sagebrush songbirds (Hethcoat and Chalfoun 2015) and the Greater Sage-Grouse (Centrocercus urophasianus; LeBeau et al. 2014) increased with natural gas and wind energy development, whereas other energy development studies suggest neutral (Hatchett et al. 2013) or even positive (Rubenstahl et al. 2012) relationships between energy development and nest predation. Recent ground-breaking work suggests that noise pollution is one of the factors by which energy development (and other human activities) can alter local trophic and predator-prey dynamics (Francis et al. 2009, 2011).

The presence of humans alone can have varying effects on nest predation rates. Adelie Penguin (Pygoscelis adeli$a e$ ) hatching success and chick survival decreased with recreational visits by humans as a result of an increase of nest predation by skuas (Giese 1996). Nest predation has been invariant with respect to other indices of human presence and activity, however, such as proximity to recreational trails (e.g. Lindsay et al. 2008). Potential investigator effects on rates of nest predation have been a concern in nest survival studies, so that ambient nest 
survival rates are documented accurately. Investigator effects, however, have been rare (Ibáñez-Alámo et al. 2012) and for some species, inversely related to nest predation (e.g. Ibáñez-Alámo and Soler 2010b).

The introduction of alien species is another human activity that typically increases nest predation. For example, the introduction of rats and other non-native mammals has been responsible for the extinction and endangerment of many birds through their nest predation activities, especially for burrow-nesting birds and those on islands (reviews: Steadman 2006; Jones et al. 2007). Feral cats are a particularly pervasive problem as predators of bird nests and adult birds (Nogales et al. 2013). Eradication of nonnative predators is often extremely challenging, and the success of eradication programs can depend on other factors, such as whether all non-native predator species are simultaneously removed to eliminate compensatory nest mortality (Oppel et al. 2014).

To understand how anthropogenic change and human disturbance affect nest predation requires knowing the ecology of nest predators (Chalfoun et al. 2002a, b; Thompson and Burhans 2003; Weatherhead and BlouinDemers 2004; Benson et al. 2010; DeGregorio et al. 2014a). A wide variety of species depredate bird nests (Ribic et al. 2012), with different relative importance of each nest predator for each bird species (Rodewald and Kearns 2011; Cox et al. 2012b; Hethcoat and Chalfoun 2015). In fact, even the relevance of a single nest predator can vary among habitats (Thompson and Burhans 2003; DeGregorio et al. 2014b). Moreover, different nest predator species respond uniquely to habitat change (Chalfoun et al. 2002a, b; Marzluff and Neatherlin 2006). A critical first step in mechanistic studies of nest predation in humanaltered environments is therefore the identification of the major nest predator species, which while logistically challenging, pays large dividends in terms of understanding nest predation risk (Rodewald and Kearns 2011; Cox et al. 2012b, c; Ribic et al. 2012). Increased nest predation can result from multiple pathways, including increased predator abundance, activity and/or effectiveness. Simultaneous study of nest predation rates and nest predator abundance and/or behaviour across the same habitat gradients has therefore clarified mechanistic pathways of nest predation dynamics (Marzluff and Neatherlin 2006; Francis et al. 2009; Benson et al. 2010; Rodewald and Kearns 2011; Cox et al. 2012b, c; DeGregorio et al. 2014a, b). Further investigations of the prevalence and effectiveness of parental and offspring nest defence tactics to particular nest predators in altered environments (Ribic et al. 2012; Bonnington et al. 2013) would also lead to a more holistic understanding of the contexts under which anthropogenic change is likely to elevate or reduce nest predation risk.
Climate change will impose additional complexity in terms of clarifying the causes of nest predation. Where ectothermic predators such as snakes are important, warming temperatures may increase nest predation rates (Cox et al. 2013; DeGregorio et al. 2014b). Over the long term, however, the influence of climate change will likely affect nest predation rates synergistically with other environmental stressors, and will depend on shifts in the distribution and behaviour of co-occurring predators and prey. Many frontiers remain in terms of understanding how nest predation dynamics will be affected by human-induced rapid environmental change such as climate change. Such frontiers will likely only be successfully conquered via careful study of the interactions between predators, prey and habitats.

\section{Biases that currently exist in nest predation research}

Future research in nest predation should address remaining biases including methodological approaches, focal species and study regions. Utilization of artificial nests is still widespread among the scientific community (e.g. Vetter et al. 2013; Selva et al. 2014) even though artificial nests often produce unrealistic patterns of nest predation (e.g. Weidinger 2001; Zanette 2002; Moore and Robinson 2004). The use of artificial nests can provide complementary and useful information for addressing some questions (e.g. Villard and Pärt 2004; Price and Banks 2012) and does allow one to test interesting hypotheses once specific nest predators of interest have been identified. Reduction of the costs of using camera technology should offer opportunities to investigate nest predator communities as well as nest predation patterns using real (and active) nests rather than artificial nests.

Passerines seem to be the focus of a disproportionate amount of nest predation studies. There is a general lack of investigations in other groups of birds (i.e. charadriiforms), which could provide significant information in some topics like the effect of coloniality or antipredator strategies of non-altricial species. Two recent studies with non-passerines show that attention on other groups of birds may help advance our understanding of nest predation. For example, Eurasian Roller nestlings have shown active chemical defence against nest predators, something not previously confirmed for passerines (Parejo et al. 2013). Furthermore, a study with the Great Spotted Cuckoo found that the antipredator repellent secretion produced by chicks of this species can benefit parasitized host nestlings, changing a classic brood parasitic relationship into a mutualistic interaction (Canestrari et al. 2014). 
As expected, a geographic bias also exists in nest predation research. Most studies focus on forested temperate regions, while tropical regions are underrepresented (Vetter et al. 2013). Increasingly some research groups are focusing work in tropical areas (e.g. Martin et al. 2000, 2015; Ghalambor and Martin 2001; Shaw and Cresswell 2014), but we urge scientists with access to these and other relatively unstudied areas (i.e. boreal regions or arid habitats) to initiate the collection of baseline nesting and nest predator data.

\section{Conclusions and future directions}

Here we present a brief overview of the most important remaining frontiers in nest predation research. From the adults' point of view, knowledge of the full suite of cues and the mechanisms involved in nest site selection is lacking, and may be instrumental to future conservation planning. Additionally, factors influencing variation in the degree or direction of parental care responses to changes in nest predation risk are not yet well understood. In particular, inconsistent results across studies investigating parental investment in egg size and number given changes in nest predation risk highlight the need for further testing. A comparative experimental approach may help elucidate what factors constrain or favour plasticity in these two traits across species.

An offspring perspective also offers opportunities for further research. Young take an active role in managing the risk of predation by gathering relevant information about risk from parents, predators and other species, and respond appropriately according to their capability, vulnerability and the type of threat. Future studies in nest predation will be especially valuable if they focus on the development and ecological significance of eavesdropping, and the importance of direct assessment of danger. Another promising line of inquiry regarding offspring is the effect of maternal effects on nestling responses, as a source of prenatal information about risk. Females exposed to predator cues before laying can have nestlings that differ in physiology or behaviour, which could be at least partly an adaptive response to risk.

In addition, the study of nest predation will be also greatly enhanced via additional study of predators. Important nest predator species must be identified and not just assumed. The mechanisms of nest site detection by predators, moreover, and potential strategies prey use to avoid eavesdropping seem to be particularly promising future lines of inquiry.

Furthermore, our understanding of nest predation effects on individual physiology is still in its infancy. A more complete comprehension of the mechanisms underlying adaptive antipredator strategies will require integration of ecological and physiological approaches. In doing so, more species should be investigated, with a special emphasis on offspring physiological changes. It will be useful to also integrate new ways of exploring the impact of nest predation, for example through the use of neurobiology (Clinchy et al. 2013), other cues (i.e. visual) in experiments, or the inclusion of additional immunological indexes. But possibly the most crucial contribution will be to investigate whether physiological changes (for adults or young) are adaptive.

From a more general perspective, differences in antipredator responses between ecological and evolutionary time deserve more attention. Interspecific comparative studies in trait responses to nest predation will complement our general understanding of factors influencing phenotypic plasticity of prey. For example, a comparative approach can help uncover potential costs associated with changes in nest predation risk that may constrain the degree of the response. Additionally, costs associated with selection of one trait can cascade down to influence traits across different life stages (e.g. Martin 2014). A focus on the demographic consequences of nest predation risk interacting with other important population level processes will also be important (e.g. Zanette et al. 2011; Sofaer et al. 2014), as they are crucial to detect the adaptive value of antipredator responses.

Finally, from a conservation standpoint, improved understanding of the mechanisms underlying variation in nest predation risk will be particularly critical in areas with human-induced habitat change. Such understanding will benefit from concomitant study of important nest predators and prey, across relevant habitat gradients and spatial scales. Other challenges regarding nest predation research that still remain are the study of other bird groups beyond passerines or other geographical areas different from the most commonly studied forested temperate regions. We hope that the forthcoming years will be fruitful in expanding our knowledge about this crucial selective force for birds.

Acknowledgments We would like to thank the organizers of the 26th International Ornithological Congress (IOC) for hosting our symposium, the seed for this paper. JDIA would like to thank his family for constant support. RDM and TMH would like to thank all who have helped in this work, especially Golo Maurer and Dirk Platzen, and the Australian Research Council for funding. JCO would like to thank the Wildlife Biology program at the University of Montana and the IOU for travel support to attend the IOC. ADC would like to thank the International Programs at the University of Wyoming for travel support to the IOC. RLT would like to thank the University of Turku Collegium for Science and Medicine for the funding to cover travel to the IOC.

Open Access This article is distributed under the terms of the Creative Commons Attribution License which permits any use, distribution, and reproduction in any medium, provided the original author(s) and the source are credited. 


\section{References}

Amo L, Galván I, Tomás G, Sanz JJ (2008) Predator odour recognition and avoidance in a songbird. Funct Ecol 22:289-293

Amo L, Visser ME, van Oers K (2011) Smelling out predators is innate in birds. Ardea 99:177-184

Benson TJ, Brown JD, Bednarz JC (2010) Identifying predators clarifies predictors of nest success in a temperate passerine. J Anim Ecol 79:225-234

Biancucci L, Martin TE (2008) First description of the breeding biology and natural history of the Ochre-breasted Brush Finch (Atlapetes semirufus) in Venezuela. Wilson J Ornithol 120:856-862

Biancucci L, Martin TE (2010) Can selection on nest size from nest predation explain the latitudinal gradient in clutch size? J Anim Ecol 79:1086-1092

Bollinger EK, Gavin TA (1989) The effects of site quality on breeding-site fidelity in Bobolinks. Auk 106:584-594

Bonnington C, Gaston KJ, Evans KL (2013) Fearing the feline: domestic cats reduce avian fecundity through trait-mediated indirect effects that increase nest predation by other species. J App Ecol 50:15-24

Bosque C, Bosque MT (1995) Nest predation as a selective factor in the evolution of developmental rates in altricial birds. Am Nat 145:234-260

Boulinier T, Danchin E (1997) The use of conspecific reproductive success for breeding patch selection in terrestrial migratory species. Evol Ecol 11:505-517

Butler LK, Bisson I, Hayden TJ, Wikelski M, Romero LM (2009) Adrenocortical responses to offspring-directed threats in two open-nesting birds. Gen Comp Endocrinol 162:313-318

Campobello D, Sará M, Hare JF (2012) Under my wing: lesser kestrels and jackdaws derive reciprocal benefits in mixed-species colonies. Behav Ecol 23:425-433

Canestrari D, Bolopo D, Turlings TCJ, Röder G, Marcos JM, Baglione V (2014) From parasitism to mutualism: unexpected interactions between a cuckoo and its host. Science 343:1350-1352

Caro TM (2005) Antipredator defences in birds and mammals. Chicago University Press, Chicago

Caro SP, Balthazart J (2010) Pheromones in birds: myth or reality? J Comp Physiol A 196:751-766

Chace JF, Walsh JJ (2006) Urban effects on native avifauna: a review. Lands Urb Plann 74:46-69

Chalfoun AD, Martin TE (2010a) Facultative nest patch shifts in response to nest predation risk in the brewer's sparrow: "a winstay, lose-switch" strategy? Oecologia 163:885-892

Chalfoun AD, Martin TE (2010b) Parental investment decisions in response to ambient nest-predation risk versus actual predation on the prior nest. Condor 112:701-710

Chalfoun AD, Ratnaswamy MJ, Thompson FR III (2002a) Songbird nest predators in forest pasture edge and forest interior in a fragmented landscape. Ecol Appl 12:858-867

Chalfoun AD, Thompson FR III, Ratnaswamy MJ (2002b) Nest predators and fragmentation: a review and meta-analysis. Conserv Biol 16:306-318

Charlesworth B (1980) Evolution in age-structured populations. Cambridge University Press, Cambridge

Cheng YR, Martin TE (2012) Nest predation risk and growth strategies of passerine species: grow fast or develop traits to escape risk? Am Nat 180:285-295

Clinchy M, Zanette L, Boonstra R, Wingfield JC, Smith JNM (2004) Balancing food and predator pressure induces chronic stress in songbirds. Proc R Soc Lond B 271:2473-2479
Clinchy M, Zanette L, Charlier TD, Newman AEM, Schmidt KL, Boonstra R, Soma KK (2011) Multiple measures elucidate glucocorticoid responses to environmental variation in predation threat. Oecologia 166:607-614

Clinchy M, Sheriff MJ, Zanette LY (2013) Predator-induced stress and the ecology of fear. Funct Ecol 27:56-65

Constantini D (2014) Oxidative stress and hormesis in evolutionary ecology and physiology. Springer, Berlin

Coslovsky M, Richner H (2011a) Increased predation risk on mothers affects survival of parasites feeding on the offspring. Anim Behav 81:1071-1075

Coslovsky M, Richner H (2011b) Predation risk affects offspring growth via maternal effects. Funct Ecol 25:878-888

Coslovsky M, Groothuis T, de Vries B, Richner H (2012) Maternal steroids in egg yolk as a pathway to translate predation risk to offspring: experiments with great tits. Gen Comp Endocrinol 176:211-214

Cott HB (1940) Adaptive coloration in animals. Oxford University Press, New York

Cox WA, Pruett MS, Benson TJ, Chiavacci SJ, Thompson III FR (2012a) Development of camera technology for monitoring nests. In: Ribic CA, Thompson III FR, Pietz PJ (eds) Video surveillance of nesting birds. Studies in avian biology, vol 43. University of California Press, Berkeley, pp 185-210

Cox WA, Thompson FR III, Faaborg J (2012b) Species and temporal factors affect predator-specific rates of nest predation for forest songbirds in the Midwest. Auk 129:147-155

Cox WA, Thompson FR III, Faaborg J (2012c) Landscape forest cover and edge effects on songbird nest predation vary by nest predator. Lands Ecol 27:659-669

Cox WA, Thompson FR III, Reidy JL (2013) The effects of temperature on nest predation by mammals, birds, and snakes. Auk 130:784-790

Cresswell W (2008) Non-lethal effects of predation in birds. Ibis 150:3-17

Dall SRX, Giraldeau LA, Olsson O, McNamara JM, Stephens DW (2005) Information and its use by animals inevolutionary ecology. Trends Ecol Evol 20:187-193

Dalziell AH, Welbergen JA, Igic B, Magrath RD (2014) Avian vocal mimicry: a unified conceptual framework. Biol Rev. doi:10. 1111/brv.12129

Davies NB, Madden JR, Butchart SHM (2004) Learning fine-tunes a specific response of nestlings to the parental alarm calls of their own species. Proc R Soc Lond B 271:2297-2304

DeGregorio BA, Chiavacci SJ, Weatherhead PJ, Willson JD, Benson TJ, Sperry JH (2014a) Snake predation on North American bird nests: culprits, patterns and future directions. J Avian Biol 45:325-333

DeGregorio BA, Weatherhead PJ, Sperry JH (2014b) Power lines, roads and avian nest survival: effects on predator identity and predation intensity. Ecol Evol 4:1589-1600

Doligez B, Danchin E, Clobert J (2002) Public information and breeding habitat selection in a wild bird population. Science 297:1168-1170

Doligez B, Cadet C, Danchin E, Boulinier T (2003) When to use public information for breeding habitat selection? The role of environmental predictability and density dependence. Anim Behav 66:973-988

Dufty AM, Crandall MB (2005) Corticosterone secretion in response to adult alarm calls in American Krestels. J Field Ornithol 76:319-325

Dumbacher JP, Pruett-Jones S (1996) Avian chemical defence. Curr Ornithol 13:137-174

Dunn E (1977) Predation by weasels (Mustela nivalis) on breeding tits (Parus spp.) in relation to the density of tits and rodents. J Anim Ecol 46:633-652 
Eggers S, Griesser M, Nystrand M, Ekman J (2006) Predation risk induces changes in nest-site selection and clutch size in the Siberian jay. Proc R Soc Lond B 273:701-706

Eichholz MW, Dassow JA, Stafford JD, Weatherhead PJ (2012) Experimental evidence that nesting ducks use mammalian urine to assess predator abundance. Auk 129:638-644

Emmering QC, Schmidt KA (2011) Nesting songbirds assess spatial heterogeneity of predatory chipmunks by eavesdropping on their vocalizations. J Anim Ecol 80:1305-1312

Fletcher RJ Jr (2008) Social information and community dynamics: non-target effects from simulating social cues for management. Ecol Appl 18:1764-1773

Fontaine JJ, Martin TE (2006) Parent birds assess nest predation risk and adjust their reproductive strategies. Ecol Lett 9:428-434

Fontaine JJ, Arriero E, Schwabl H, Martin TE (2011) Nest predation and circulating corticosterone levels within and among species. Condor 113:825-833

Forsman JT, Martin TE (2009) Habitat selection for parasite-free space by hosts of parasitic cowbirds. Oikos 118:464470

Forsman JT, Mönkkönen M, Korpimäki E, Thomson RL (2013) Mammalian nest predator feces as a cue in avian habitat selection decisions. Behav Ecol 24:262-266

Francis CD, Ortega CP, Cruz A (2009) Noise pollution changes avian communities and species interactions. Curr Biol 19:1415-1419

Francis CD, Paritsis J, Ortega CP, Cruz A (2011) Landscape patterns of avian habitat use and nest success are affected by chronic gas well compressor noise. Lands Ecol 26:1269-1280

Fridinger RW, O'Reilly KM, Kildaw SD, Buck CL (2007) Removal of a nest-mate elicits an age-dependent increase in plasma corticosterone of nestling Black-legged Kittiwakes. J Field Ornithol 78:93-99

Gartner GEA, Greene HW (2008) Adaptation in the African eggeating snake: a comparative approach to a classic study in evolutionary functional morphology. J Zool 275:368-374

Ghalambor CK, Martin TE (2001) Fecundity-survival trade-offs and parental risk-taking in birds. Science 292:494-497

Ghalambor CK, Peluc SI, Martin TE (2013) Plasticity of parental care under the risk of predation: how much should parents reduce care? Bio Lett 9:20130154

Giese M (1996) Effects of human activity on Adelie penguin Pygoscelis adeliae breeding success. Biol Conserv 75:157-164

Glutz Von Blotzheim UN, Bauer K (1980) Handbuch der Vögel Mitteleuropas, vol 9. Akademische Verlagsgesellschaft, Weisbaden

Goedert D, Dias RI, Macedo RH (2014) Nestling use of alternative acoustic antipredator responses is related to immune condition and social context. Anim Behav 91:161-169

Goodale E, Beauchamp G, Magrath RD, Nieh JC, Ruxton GD (2010) Interspecific information transfer influences animal community structure. Trends Ecol Evol 25:354-361

Greig-Smith PW (1982) Dispersal between nest-sites by stonechats Saxicola torquata in relation to previous breeding success. Ornis Scand 13:232-238

Haff TM, Magrath RD (2010) Vulnerable but not helpless: nestlings are fine-tuned to cues of approaching danger. Anim Behav 79:487-496

Haff TM, Magrath RD (2011) Calling at a cost: elevated nestling calling attracts predators to active nests. Biol Lett 7:493-495

Haff TM, Magrath RD (2012) Learning to listen? Nestling response to heterospecific alarm calls. Anim Behav 84:1401-1410

Haff TM, Magrath RD (2013) Eavesdropping on the neighbours: fledgling response to heterospecific alarm calls. Anim Behav 85:411-418

Haff TM, Horn AG, Leonard ML, Magrath RD (2015) Conspicuous calling near cryptic nests: a review of hypotheses and a field study on white-browed scrubwrens. J Avian Biol. doi:10.1111/ jav.00622

Hagelin JC, Jones IL (2007) Birds odors and other chemical substances: a defense mechanism or overlooked mode of intraspecific communication. Auk 124:1-21

Häkkila M, Halme P, Koskela E (2012) Could fluctuating prey availability change protective nesting associations in forest birds? A hypothesis. J Ornith 153:199-203

Hatchett ES, Hale AM, Bennett VJ, Karsten KB (2013) Wind turbines do not negatively affect nest success in the dickcissel (Spiza americana). Auk 130:520-528

Hettena AM, Munoz N, Blumstein DT (2014) Prey responses to predator's sounds: a review and empirical study. Ethology 120:427-452

Hethcoat MG, Chalfoun AD (2015) Energy development and avian survival in Wyoming, USA: a test of a common disturbance index. Biol Conserv 184:327-334

Hildén O (1965) Habitat selection in birds. Rev Ann Zool Fenn 2:53-75

Hoover JP (2003) Decision rules for site fidelity in a migratory bird, the prothonotary warbler. Ecology 84:416-430

Hua F, Fletcher RJ Jr, Sieving KE, Dorazio RM (2013) Too risky to settle: avian community structure changes in response to perceived predation risk on adults and offspring. Proc R Soc Lond B 280:20130762

Hua F, Sieving KE, Fletcher RJ, Wright CA (2014) Increased perception of predation risk to adults and offspring alters avian reproductive strategy and performance. Behav Ecol 25:509-519

Hulbert AJ, Pamplona R, Buffenstein R, Buttemer WA (2007) Life and death: metabolic rate, membrane composition, and life span of animals. Physiol Rev 87:1175-1213

Ibáñez-Alámo JD, Soler M (2010a) Does urbanization affect selective pressures and life-history strategies in the common blackbird (Turdus merula L.)? Biol J Linn Soc 101:759-766

Ibáñez-Alámo JD, Soler M (2010b) Investigator activities reduce nest predation in blackbirds Turdus merula. J Avian Biol 41:208-212

Ibáñez-Álamo JD, Soler M (2012) Predator-induced female behavior in the absence of male incubation feeding: an experimental study. Behav Ecol Sociobiol 66:1067-1073

Ibáñez-Alámo JD, Sanllorente O, Soler M (2012) The impact of researcher disturbance on nest predation rates: a meta-analysis. Ibis 154:5-14

Ibáñez-Álamo JD, Chastel O, Soler M (2011) Hormonal responses of nestlings to predator calls. Gen Comp Endocrinol 171:232-236

Ibáñez-Álamo JD, Arco L, Soler M (2012) Experimental evidence for a predation cost of begging using active nests and real chicks. J Ornithol 153:801-807

Ibáñez-Álamo JD, Sanllorente O, Arco L, Soler M (2013) Does nest predation risk induce parent birds to eat nestlings' fecal sacs? An experimental study. Ann Zool Fenn 50:71-78

Ibáñez-Álamo JD, Ruiz-Raya F, Roncalli G, Soler M (2014) Is nest predation an important selective pressure determining fecal sac removal? The effect of olfactory cues. J Ornithol 155:491-496

Jones HP, Tershy BR, Zavaleta ES, Croll DA, Keitt BS, Finkelstein ME, Howald GR (2007) Severity of the effects of invasive rats on seabirds: a global review. Conserv Biol 22:16-26

Kearns LJ, Rodewald AD (2013) Within-season use of public and private information on predation risk in nest-site selection. J Ornithol 154:163-172

Kilner RM (2006) The evolution of egg colour and patterning in birds. Biol Rev 81:383-406

Kitaysky AS, Kitaiskaia EV, Piatt JF, Wingfield JC (2003) Benefits and costs of increased levels of corticosterone in seabird chicks. Horm Behav 43:140-149 
Kleindorfer S, Sulloway FJ, O'Connor J (2009) Mixed species nesting associations in Darwin's tree finches: nesting pattern predicts predation outcome. Biol J Linn Soc 98:313-324

Krama T, Krams I (2005) Cost of mobbing call to breeding pied flycatcher, Ficedula hypoleuca. Behav Ecol 16:37-40

Krams I, Krama T, Igaune K, Mänd R (2007) Long-lasting mobbing of the pied flycatcher increases the risk of nest predation. Behav Ecol 18:1082-1084

Lack D (1947) The significance of clutch size. Ibis 89:302-352

Lack D (1948) The significance of clutch size. Part III. Some interspecific comparisons. Ibis 90:25-45

Lahti DC (2001) The "edge effect on nest predation" hypothesis after twenty years. Biol Conserv 99:365-374

LaManna JA, Hemenway AB, Boccadori V, Martin TE (2015) Bird species turnover is related to changing predation risk along a vegetation gradient. Ecology. doi:10.1890/14-1333.1

Law R (1979) Optimal life histories under age-specific predation. Am Nat 114:399-417

LeBeau CW, Beck JL, Johnson GD, Holloran MJ (2014) Short-term impacts of wind energy development on greater sage-grouse fitness. J Wild Manag 78:522-530

Lee W-S, Monaghan P, Metcalfe NB (2013) Experimental demonstration of the growth rate-lifespan trade-off. Proc R Soc Lond B 280(2012):2370

Libsch MM, Batista C, Buehler D, Ochoa I, Brawn J, Ricklefs RE (2008) Nest predation in a neotropical forest occurs during daytime. Condor 110:166-170

Lima SL (1998) Nonlethal effects in the ecology of predator-prey interactions. Bioscience 48:25-34

Lima SL (2002) Putting predators back into behavioral predator-prey interactions. Trends Ecol Evol 17:70-75

Lima SL (2009) Predators and the breeding bird: behavioral and reproductive flexibility under the risk of predation. Biol Rev $84: 485-513$

Lindsay K, Craig J, Low M (2008) Tourism and conservation: the effects of track proximity on avian reproductive success and nest selection in an open sanctuary. Tour Manag 29:730-739

Loukola OJ, Seppänen JT, Forsman JT (2012) Intraspecific social information use in the selection of nest site characteristics. Anim Behav 83:629-633

Loukola OJ, Laaksonen T, Seppänen JT, Forsman JT (2014) Active hiding of social information from information-parasites. BMC Evol Biol 14:32

Madden JR, Kilner RM, Davies NB (2005) Nestling responses to adult food and alarm calls: 1 . Species specific responses in two cowbird hosts. Anim Behav 70:619-627

Magrath RD, Platzen D, Kondo J (2006) From nestling calls to fledgling silence: adaptive timing of change in response to aerial alarm calls. Proc R Soc Lond B 273:2335-2341

Magrath RD, Pitcher BJ, Dalziell AH (2007) How to be fed but not eaten: nestling responses to parental food calls and the sound of a predator's footsteps. Anim Behav 74:1117-1129

Magrath RD, Haff TM, Horn A, Leonard ML (2010) Calling in the face of danger: predation risk and acoustic communication by parent birds and their offspring. Adv Study Behav 41:187-253

Magrath RD, Haff TM, Fallow PM, Radford AN (2014) Eavesdropping on heterospecific alarm calls: from mechanisms to consequences. Biol Rev. doi:10.1111/brv.12122

Martin TE (1987) Food as a limit on breeding birds: a life-history perspective. Ann Rev Ecol Syst 18:453-487

Martin TE (1988a) Processes organizing open-nesting bird assemblages: competition or nest predation? Evol Ecol 2:37-50

Martin TE (1988b) Habitat and area effects on forest bird assemblages: is nest predation an influence? Ecology 69:74-84

Martin TE (1991) Food limitation in terrestrial breeding birds: is that all there is? Acta Congr Int Orn 20:1595-1602
Martin TE (1992) Interaction of nest predation and food limitation in reproductive strategies. Curr Ornithol 9:163-197

Martin TE (1993a) Nest predation and nest sites: new perspectives on old patterns. Bioscience 43:523-532

Martin TE (1993b) Nest predation among vegetation layers and habitat types: revising the dogmas. Am Nat 141:897-913

Martin TE (1995) Avian life history evolution in relation to nest sites, nest predation and food. Ecol Monogr 65:101-127

Martin TE (2002) A new view for avian life history evolution tested on an incubation paradox. Proc R Soc Lond B 269:309-316

Martin TE (2004) Avian life-history evolution has an eminent past: does it have a bright future? Auk 121:289-301

Martin TE (2014) A conceptual framework for clutch-size evolution in songbirds. Am Nat 183:313-324

Martin TE, Briskie JV (2009) Predation on dependent offspring. Ann NY Acad Sci 1168:201-217

Martin TE, Schwabl H (2008) Variation in maternal effects and embryonic development rates among passerine species. Phil Trans Roy Soc B 363:1663-1674

Martin TE, Martin PR, Olson CR, Heidinger BJ, Fontaine JJ (2000) Parental care and clutch sizes in North and South American birds. Science 287:1482-1485

Martin TE, Bassar RD, Bassar SK, Fontaine JJ, Lloyd P, Mathewson HA, Niklison AM, Chalfoun A (2006) Life-history and ecological correlates of geographic variation in egg and clutch mass among passerine species. Evolution 60:390-398

Martin TE, Auer SK, Bassar RD, Niklison A, Lloyd P (2007) Geographic variation in avian incubation periods and parental influences on embryonic temperature. Evolution 61:2558-2569

Martin TE, Lloyd P, Bosque C, Barton DC, Biancucci AL, Cheng YR, Ton $R$ (2011) Growth rate variation among passerine species in tropical and temperate sites: an antagonistic interaction between parental food provisioning and nest predation risk. Evolution 65:1607-1622

Martin TE, Oteyza JC, Mitchell AE, Potticary AL, Lloyd P (2015) Post-natal growth rates covary weakly with embryonic development rates and do not explain adult mortality probability among songbirds on four continents. Am Nat 185:380-389

Marzluff JM, Neatherlin E (2006) Corvid response to human settlements and campgrounds: causes, consequences, and challenges for conservation. Biol Conserv 130:301-314

Matson KD, Cohen AA, Klasing KC, Ricklefs RE, Scheuerlein A (2006) No simple answers for ecological immunology: relationships among immune indices at the individual level break down at the species level in waterfowl. Proc $\mathrm{R}$ Soc Lond $\mathrm{B}$ 273:815-822

Maynard Smith J, Harper D (2003) Animal signals. Oxford University Press, Oxford

McCay CM (1933) Is longevity compatible with optimum growth? Science 77:410-411

McDonald PG, Wilson DR, Evans C (2009) Nestling begging increases predation risk, regardless of spectral characteristics or avian mobbing. Behav Ecol 20:821-829

McKinnon L, Berteaux D, Bêty J (2014) Predator-mediated interactions between lemmings and shorebirds: a test of the alternative prey hypothesis. Auk 131:619-628

Metcalfe NB, Monaghan P (2003) Growth versus lifespan: perspectives from evolutionary ecology. Exp Geront 38:935-940

Michod RE (1979) Evolution of life histories in response to agespecific mortality factors. Am Nat 113:531-550

Mönkkönen M, Husby M, Tornberg R, Helle P, Thomson RL (2007) Predation as a landscape effect: the trading off by prey species between predation risks and protection benefits. J Anim Ecol 76:619-629

Mönkkönen M, Forsman JT, Kananoja T, Ylönen H (2009) Indirect cues of nest predation risk and avian reproductive decisions. Biol Lett 5:176-178 
Moore RP, Robinson WD (2004) Artificial nest birds, external validity, and bias in ecological field studies. Ecology 85:1562-1567

Moreau RE (1944) Clutch size: a comparative study, with reference to African birds. Ibis 86:286-347

Morosinotto C, Thomson RL, Hänninen M, Korpimäki E (2012) Higher nest predation risk in association with a top predator: mesopredator attraction? Oecologia 170:507-515

Morosinotto C, Thomson RL, Korpimäki E (2013a) Plasticity in incubation behavior under experimentally prolonged vulnerability to nest predation. Behaviour 150:1767-1786

Morosinotto C, Ruuskanen S, Thomson RL, Siitari H, Korpimäki E, Laaksonen $\mathrm{T}(2013 \mathrm{~b})$ Predation risk affects the levels of maternal immune factors in avian eggs. J Avian Biol 44:427-436

Mutzel A, Blom MP, Spagopoulou F, Wright J, Dingemanse NJ, Kempenaers B (2013) Temporal trade-offs between nestling provisioning and defence against nest predators in blue tits. Anim Behav 85:1459-1469

Nogales M, Vidal E, Medina FM, Bonnaud E, Tershy BR, Karl J, Campbell KJ, Zavaleta ES (2013) Feral cats and biodiversity conservation: the urgent prioritization of island management. Bioscience 63:804-810

Olsson M, Shine R (2002) Growth to death in lizards. Evolution 56:1867-1870

Oppel S, Burns F, Vickery J, George K, Ellick G, Leio D, Hillman JC (2014) Habitat-specific effectiveness of feral cat control for the conservation of an endemic ground-nesting bird species. J App Ecol 51:1246-1254

Owings DH, Rowe MP, Rundus AS (2002) The rattling sound of rattlesnakes (Crotalus viridis) as a communicative resource for ground squirrels (Spermophilus beecheyi) and burrowing owls (Athene cunicularia). J Comp Psych 116:197-205

Pakanen V-M, Rönkä N, Thomson RL, Koivula K (2014) Informed renesting decisions: the effect of nest predation risk. Oecologia 174:1159-1167

Parejo D, Pérez-Contreras T, Navarro C, Soler JJ, Avilés JM (2008) Spotless starlings rely on public information while visiting conspecific nests: an experiment. Anim Behav 75:483-488

Parejo D, Avilé JM, Peña A, Sánchez L, Ruano F, Zamora-Muñoz C, Martín-Vivaldi M (2013) Armed rollers: does nestling's vomit function as a defence against predators? PLoS ONE 8:e68862

Pärt T, Arlt D, Doligez B, Low M, Qvarnström A (2011) Prospectors combine social and environmental information to improve habitat selection and breeding success in the subsequent year. J Anim Ecol 80:1227-1235

Pelech SA, Smith JNM, Boutin S (2010) A predator's perspective of nest predation: predation by red squirrels is learned, not incidental. Oikos 119:841-851

Peluc SI, Sillet TS, Rotenberry JT, Ghalambor CK (2008) Adaptive phenotypic plasticity in an island songbird exposed to a novel predation risk. Behav Ecol 19:830-835

Piper WH (2011) Making habitat selection more familiar: a review. Behav Ecol Sociobiol 65:1329-1351

Platzen D, Magrath RD (2005) Adaptive differences in response to two types of parental alarm calls in altricial nestlings. Proc $\mathrm{R}$ Soc Lond B 272:1101-1106

Polak M (2014) Protective nesting association between the Barred Warbler Sylvia nisoria and the Red-backed Shrike Lanius collurio: an experiment using artificial and natural nests. Ecol Res 29:949-957

Price CJ, Banks PB (2012) Exploiting olfactory learning in alien rats to protect birds' eggs. Proc Natl Acad Sci 109:19304-19309

Quinn JL, Ueta M (2008) Protective nesting associations in birds. Ibis 150(S1):146-167

Rajchard J (2009) Ultraviolet (UV) light perception by birds: a review. Vet Med 54:351-359
Remeš V (2007) Avian growth and development rates and agespecific mortality: the roles of nest predation and adult mortality. J Evol Biol 20:320-325

Remeš V, Martin TE (2002) Environmental influences on the evolution of growth and developmental rates in passerines. Evolution 56:2505-2518

Ribic CA, Thompson III FR, Pietz PJ (eds) (2012) Video surveillance of nesting birds. Studies in avian biology, vol 43. University of California Press, Berkeley

Richardson TW, Gardali T, Jenkins SH (2009) Review and metaanalysis of camera effects on avian nest success. J Wild Manag 73:287-293

Ricklefs RE (2000) Lack skutch, and moreau: the early development of life-history thinking. Condor 102:3-8

Rivers JW, Martin LB, Liebl AL, Betts MG (2011) Parental alarm calls of the white-crowned sparrow fail to stimulate corticosterone production in nest-bound offspring. Ethology 117:374-384

Rodewald AD, Kearns LJ (2011) Shifts in dominant nest predators along a rural-to-urban landscape gradient. Condor 113:899-906

Rodewald AD, Kearns LJ, Shustack DP (2011) Consequences of urbanizing landscapes to reproductive performance of birds in remnant forests. Biol Conserv 160:32-39

Rollo CD (2002) Growth negatively impacts the life span of mammals. Evol Develop 4:55-61

Roth TC, Cox JG, Lima SL (2008) Can foraging birds assess predation risk by scent? Anim Behav 76:2021-2027

Rowe MP, Coss RG, Owings DH (1986) Rattlesnake rattles and burrowing owl hisses: a case of acoustic Batesian mimicry. Ethology 72:53-71

Rubenstahl TG, Hale AM, Karsten KB (2012) Nesting success of scissor-tailed flycatchers (Tyrannus forficatus) at a wind farm in northern Texas. Southwest Nat 57:189-194

Saino N, Ferrari R, Romano M, Martinelli R, Møller AP (2003) Experimental manipulation of egg carotenoids affects immunity of barn swallow nestlings. Proc R Soc Lond B 270:2485-2489

Schmidt KA (1999) Foraging theory as a conceptual framework for studying nest predation. Oikos 85:151-160

Schmidt KA (2001) Site fidelity in habitats with contrasting levels of nest predation and brood parasitism. Evol Ecol Res 3:633-648

Schmidt KA (2004) Incidental predation, enemy-freespace and the coexistence of incidental prey. Oikos 106:335-343

Schmidt KA, Schauer EM (2007) Behavioral indicators of predatorfree space: studying species interactions through the behavior of predators. Israel J Ecol Evol 53:389-406

Schmidt KA, Whelan CJ (2010) Nesting in an uncertain world: information and sampling the future. Oikos 119:245-253

Schmidt KA, Goheen JR, Naumann R (2001) Incidental nest predation in songbirds: using behavioral indicators to determine ecological processes and scales. Ecology 82:2937-2947

Schmidt KA, Dall SRX, van Gils JA (2010) The ecology of information: an overview on the ecological significance of making informed decisions. Oikos 119:304-316

Schmidt KA, Johansson J, Kristensen N, Massol J, Jonzén N (2015) Consequences of information use in breeding habitat selection on the evolution of settlement time. Oikos 124:69-80

Schwabl H, Palacios MG, Martin TE (2007) Selection for rapid embryo development correlates with embryo exposure to maternal androgens among passerine birds. Am Nat 170:196-206

Selva N, Berezowska-Cnota T, Elguero-Claramunt I (2014) Unforeseen effects of supplementary feeding: ungulate baiting sites as hotspots for ground-nest predation. PLoS ONE 9:e90740

Seppänen JT, Forsman JT (2007) Interspecific social learning: novel preference can be copied from a competing species. Curr Biol $17: 1248-1252$ 
Seppänen JT, Forsman JT, Mönkkönen M, Thomson RL (2007) Social information use is a process across time, space, and ecology, reaching heterospecifics. Ecology 88:1622-1633

Seppänen JT, Forsman JT, Mönkkönen M, Krams I, Salmi T (2010) New behavioral trait adopted or rejected by observing heterospecific tutor fitness. Proc R Soc Lond B 278:1736-1741

Shaw P, Cresswell W (2014) Latitudinal variation in day length and working day length has a confounding effect when comparing nest attentiveness in tropical and temperate species. J Ornithol 155:481-489

Sheriff MJ, Thaler JS (2014) Ecophysiological effects of predation risk: an integration across disciplines. Oecologia 176:607-611

Silverin B (1998) Behavioral and hormonal responses of the pied flycatcher to environmental stressors. Anim Behav 55:1411-1420

Skutch AF (1949) Do tropical birds rear as many young as they can nourish? Ibis 91:430-455

Skutch AF (1976) Parent birds and their young. University of Texas Press, Austin

Smith CC, Fretwell SD (1974) The optimal balance between size and number of offspring. Am Nat 108:499-506

Sofaer HR, Sillett TS, Langin KM, Morrison SA, Ghalambor CK (2014) Partitioning the sources of demographic variation reveals density-dependent nest predation in an island bird population. Ecol Evol 4:2738-2748

Sonerud GA, Fjeld PE (1987) Long-term memory in egg predators: an experiment with a hooded crow. Ornis Scand 18:323-325

Steadman DW (2006) Extinction and biogeography of tropical Pacific birds. University of Chicago Press, Chicago

Stoddard MC, Marshall KL, Kilner RM (2011) Imperfectly camouflaged avian eggs: artefact or adaptation? Avian Biol Res 4:196-213

Suzuki TN (2011) Parental alarm calls warn nestlings about different predatory threats. Curr Biol 21:15-16

Szymkoviak J, Kuczyński L (2015) Avoiding predators in a fluctuating environment: responses of the wood warbler to pulsed resources. Behav Ecol 26:601-608

Thompson FR III, Burhans DE (2003) Predation of songbird nests differs by predator and between field and forest habitats. J Wild Manag 67:408-416

Thomson RL, Forsman JT, Sarda-Palomera F, Mönkkönen M (2006) Fear factor: prey habitat selection and its consequences in a predation risk landscape. Ecography 29:507-514

Thomson RL, Tomás G, Forsman JT, Broggi J, Mönkkönen M (2010) Predator proximity as a stressor in breeding female flycatchers: mass loss, stress protein induction, and workload. Ecology 91:1832-1840

Thomson RL, Sirkiä PM, Villers A, Laaksonen T (2013) Temporal peaks in social information: prospectors investigate conspecific nests after a simulated predator visit. Behav Ecol Sociobiol 67:905-911

Tilgar V, Saag P, Külavee R, Mänd R (2010) Behavioral and physiological responses of nestling pied flycatchers to acoustic stress. Horm Behav 57:481-487
Tinbergen N, Broekhuysen GJ, Feekes F, Houghton JCW, Kruuk H, Szulc E (1962) Egg shell removal by the black-headed gull, Larus ridibundus L.; a behaviour component of camouflage. Behaviour 19:74-117

Tomiałojć L (1979) The impact of predation on urban and rural woodpigeon (Columba palumbus L) populations. Pol Ecol Stud 5:141-220

Travers M, Clinchy M, Zanette L, Boonstra R, Williams TD (2010) Indirect predator effects on clutch size and the cost of egg production. Ecol Lett 13:980-988

Vetter D, Rücker G, Storch I (2013) A meta-analysis of tropical forest edge effects on bird nest predation risk: edge effects in avian nest predation. Biol Conserv 159:382-395

Villard MA, Pärt T (2004) Don't put all your eggs in real nests: a sequel to Faaborg. Conserv Biol 18:371-372

Von Haartman L (1957) Adaptation in hole-nesting birds. Evolution 11:339-347

Weatherhead PJ, Blouin-Demers G (2004) Understanding avian nest predation: why ornithologists should study snakes. J Avian Biol $35: 185-190$

Węgrzyn E, Leniowski K (2015) Blackcap Sylvia atricapilla nestlings under high predation pressure do not use begging calls until they are able to fledge. Ibis 157:356-368

Weidinger K (2001) Does egg colour affect predation rate on open passerine nests? Behav Ecol Sociobiol 49:456-464

Weidinger K (2008) Nest monitoring does not increase nest predation in open-nesting songbirds: inference from continuous nestsurvival data. Auk 125:859-868

Weidinger K (2009) Nest predators of woodland open-nesting songbirds in central Europe. Ibis 151:352-360

Weidinger K (2010) Foraging behavior of nest predators at open-cup nests of woodland passerines. J Ornithol 151:729-735

Weidinger K, Kočvara R (2010) Repeatability of nest predation in passerines depends on predator species and time scale. Oikos 119:138-146

Wesołowski T, Rowiński P, Maziarz M (2009) Wood warbler Phylloscopus sibilatrix - a nomadic insectivore in search of safe breeding grounds? Bird Study 56:26-33

Wiebe KL, Moore WS (2008) Northern flicker (Colaptes auratus). In: Poole A (ed) Birds of North America online. Cornell Laboratory of Ornithology, Ithaca

Zanette L (2002) What do artificial nests tells us about nest predation? Biol Conserv 103:323-329

Zanette LY, White AF, Allen MC, Clinchy M (2011) Perceived predation risk reduces the number of offspring songbirds produce per year. Science 334:1398-1401

Zanette LY, Hobson KA, Clinchy M, Travers M, Williams TD (2013) Food use is affected by the experience of nest predation: implications for indirect predator effects on clutch size. Oecologia 172:1031-1039

Zanette LY, Clinchy M, Suraci JP (2014) Diagnosing predation risk effects on demography: can measuring physiology provide the means? Oecologia 176:637-651 